\title{
Existing Problems and Countermeasures of Marathons in Third and Fourth-Tier Cities
}

\author{
Chen $\operatorname{Ran}^{1, a}$, Chen XueFeng ${ }^{2, b^{*}}$ \\ ${ }^{1}$ College of Physical Education, Beihua University, jilin, jilin, China. \\ ${ }^{2}$ College of Education, Jilin International Studies University, changchun, jilin, China. \\ a275377842@qq.com \\ b*99746526@qq.com \\ *Corresponding author
}

\begin{abstract}
Marathon races have been developing fast in third and fourd - tier cities for nearly a decade. They not only increased the quantities of the marathon races in China, but also gained more diversity because of the different courses. However, these races revealed issues such as financial scandals, vanity motivated and lack of race management experiences. Government led, enhanced society advantages and building a strong education base will be the possible ways to solve these issues.
\end{abstract}

Keywords: marathon race, issues, solution

\section{三四线城市马拉松运动的现存问题与对策}

\author{
陈然 1 , a 陈学峰 $2, b^{*}$
}

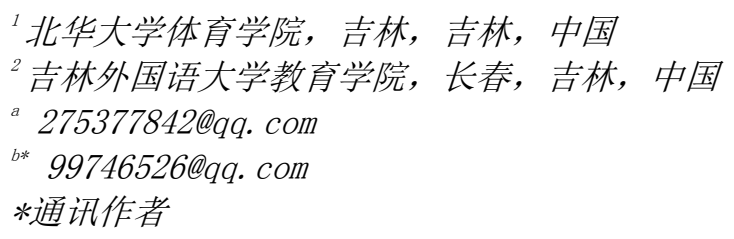

\section{摘要}

我国三四线城市马拉松运动, 在近十年的时间里有了很大的发展, 不仅扩大了中国城市马拉松运动的 规模，也在一定程度上增加了城市马拉松运动的丰富性，同时也暴露了自身在经济驱动、盲目攀比、 经验不足方面的问题。发挥政府主导、强化社会优势、奠定学校基础会在一定程度上改善相关的问题。 关键词：城市马拉松，问题，对策

\section{1. 城市马拉松运动的发展}

国外城市马拉松运动源于 1897 年波士顿马拉松, 距今已有一百二十年的历史，几乎与马拉松运动同龄， 只是把赛道由原来的固定赛道变成了不同城市的赛道, 其性质还是竞技比赛。当然在这个百十年的发展中运动 规则也有一些变化, 随着参与人数逐年增多, 大众健身 的性质也越来越明显。

中国的城市马拉松运动似乎沿袭了国外由竞赛性 到大众性演变, 虽然历史较短, 但其发展速度和规模却 让世人咋舌。1981 年首届北京马拉松, 只有 12 个国家 86 名选手, 显然也是以竞赛为目的。直到 2014 年《国 务院关于加快发展体育产业促进体育消费的若干意 见》, 2016 年《国务院办公厅关于加快发展体育休闲产
业指导意见》的出台, 中国城市马拉松开始出现由竞技 比赛到大众健身的转变。之后的快速发展和影响力超出 人们的想象 ${ }^{[1]}$ 。2016 年统计, 中国境内城市马拉松 328 场，年参加马拉松比赛人数超过 100 万，北京马拉松创 下单场马拉松 6 万人的记录。

三四线城市的马拉松运动热情, 也由此被迅速点 燃。据不完全统计, 在中国当下的马拉松热潮中, 三四 线的城市马拉松至少占有半壁江山 ${ }^{[2]}$ 。这不仅扩大了中 国城市马拉松运动的规模, 也在一定程度上丰富了中国 城市马拉松运动的内容和特色。但是由于三四线城市的 自然环境、城市规模条件、办赛经验等方面的不足, 也 出现了一些问题。系统发现问题, 形成解决问题对策, 对于中国马拉松运动的健康发展无疑有着重要意义。 
也是不适合大众参加的项目。而这些项目大都来自三四 线城市。

更值得思考的是，当记者问及到以上问题发生地的

\section{1 经济驱动}

中国城市马拉松运动蓬勃发展主要源于中国改革 开放以来的经济发展和人们生活水平提高, 以及由此带 来的精神文化需要提高。但也不能否认一些办赛城市对 于马拉松运动经济利益的过度考量, 他们看到了人们经 济生活提高以后对体育文化需求的要求, 也看到了城市 马拉松运动对地方经济带来的影响, 于是在 “体育搭台, 经济唱戏” 的理念下, 三四线城市马拉松便如雨后春笋, 在全国各地蓬勃展开, 不仅如此, 有些县级城市也加入 了城市马拉松的大军之中。城市马拉松承办模式主要是 国家体育部门发文、城市承办、企业赞助, 兼备商业性 和社会性的双重特征。然而在赛事举办以及经济价值的 驱使下, 社会价值慢慢被人们所忽略。由于三四城市马 拉松举办时间较短, 赛事的各个方面资金、设施、安全 保障等都存在着不足, 出现了重赛事运营、轻跑者体验, 重赛事规模与影响、轻跑者安全等现象 ${ }^{[3-4]}$ 。过度追求 经济利益最大化, 使马拉松运动在一定程度上偏离了健 康发展的轨道, 失去明确的发展目标和方向 ${ }^{[5]}$ 。

\section{2 盲目攀比}

在办赛规格、规模和办赛形式盲目攀比, 不顾自身 实际, 造成消化不良的后果。赛事之间互相学习、观摩 本是常有的正常之举, 但是一味攀比模仿就会带来严重 的问题。一是在形式上盲目模仿, 造成赛事的严重同质 化, 失去了自己城市的特色; 二是规模上盲目攀比, 造 成赛事组织、接待能力不足; 三是规格上盲目攀比, 造 成技术、管理和指导上的缺失。有的县级市的马拉松赛 会, 为了满足规格、规模和形式的完满, 重金聘请了多 位外籍选手; 动用各种方法大量组织县城职工、居民和 学生参加啦啦队或 “陪跑”, 结果得不偿失, 效果不好。

\section{3 经验不足}

中国城市马拉松虽然有三十多年的历史, 但是三四 线城市大规模的城市马拉松运动还不到十年的时间, 与 国外一百多年的城市马拉松运动历史相比, 整体办赛经 验明显不足 ${ }^{[6]}$ 。

一是入场、退场路线设计过于复杂，运动员入场、 退场所需时间太多、费时费力, 影响比赛, 造成滞留。 二是赛道路口开放时间不合理, 造成市民行走不便, 有 的地段还有限制经营现象, 有些扰民。三是一些特色马 拉松项目缺少有效的保障措施, 极容易造成运动伤害。 如高寒地区的冰雪马拉松、高纬度的高原马拉松、路况 不好的山地马拉松都不适合作为城市大众马拉松项目, 因为这些项目需要较好的技术与物质支撑, 没有良好的 赛事保证, 即使是个人有一定的训练基础和保障能力, 相关组织者时，他们说: 运动员入场和退场路线设计和 赛道途中严格的管控是为了比赛的安全; 选择高原、高 寒等特殊环境进行马拉松比赛是为了增加比赛特色。这 就不仅是办赛的经验问题, 至少是对大众马拉松运动科 学性认知上的缺失, 这也是让人担忧的问题。

城市马拉松运动出现一些问题, 应该也是不可避免 的, 特别是对我们这样办赛历史较短的国家, 特别是三 四线城市更是可以理解的, 在一定意义上这也是城市马 拉松运动发展中可以理解的代价。但是, 认真正视问题, 仔细分析原因、找到有效的对策才是科学的态度。因为 经验不足不应成该为办赛水平低的借口和理由。

\section{3. 三四线城市马拉松运动发展对策}

\section{1 发挥政府主导}

第一，政府主导，提高认识。城市马拉松是一个巨 大的系统工程, 政府要把马拉松这个系统工程很好融入 政府整体工作之中。要站在健康中国的角度, 研究城市 马拉松运动的规律, 要站在城市两个文明建设的角度研 究组织城市马拉松运动, 要从城市马拉松运动的经济效 益、文化效益、政治效益和社会效益与城市全面发展的 整体性上去考虑城市马拉松运动的定位。由此, 把城市 马拉松运动转化成为城市人民两个文明成果展示的盛 会; 成为城市经济、政治、文化整体发展的盛会; 成为 市民欢乐的节日。

第二, 广泛借鉴, 打造特色。发挥三四线城市后发 优势, 借鉴大城市成功经验, 形成差异化相对优势, 蕴 育自己特有的城市马拉松文化样态。整合地域、气候、 文化、传统、饮食、人文等要素做足做好 “特” 字文章。

\section{2 强化社会优势}

在政府协调性下, 强化民间马拉松运动优势, 形成 城市马拉松运动主体队伍。

第一，发挥民间 “跑团” 作用，形成优势的城市马 拉松运动主体。一般来说 “跑团” 是城市马拉松运动的 基础组织形式, 有一定的群众基础和运动基础, 一般能 反映这个城市的马拉松运动状态和水平。在这个过程中 会形成他们自己的专业带头人，成为城市马拉松的骨干 和技术力量。政府可以通过优秀跑团评比和优秀教练员 的评比等形式, 促进 “跑团” 发展, 促进城市马拉松运 动发展。

第二，促进企事业单位的马拉松文化形成。一是通 过政府部门对参与马拉松活动好的单位, 给予表彰或奖 励; 二是促进城市马拉松运动与企业产品相结合, 实现 城市马拉松与企事业文化的融合 ${ }^{[7]}$ 。 


\section{REFERENCES}

[1] Li Chun-Guang. (2018) Research on the development of happy gymnastics in China from the perspective of cross-border integration. Beijing Sport University, Beijing.

[2] Yu Bo-Yi. (2016) Simple analysis Development of marathon events in third - and fourth-tier cities in China. In:Decision forum - seminar on decision theory and methodology. Beijing. 122.

[3] Miao Guang-chao, Song Jin-zhuang, WEI Ting, LI Tie-lu. (2019) Examination and the Solutions of Marathon Events in China, Sports Culture Guide, (01):27-31.

[4] Xing Jin-ming, LIU Bo, OUYANG Jing-feng. (2017) "Cool" reflection behind marathon "heat". Journal of Physical Education, 24(02):52-56.

[5] Zhao qing-xiang. (2019) Focus and prospect:the development situation and runner features of marathon in China. Liaoning Sport Science and Technology, 41(04):25-30.

[6] Chen Ran, Chen Xue-Feng.(2019) Research on Healthy Development Strategy of Urban Marathon Based on National Fitness_-Taking Jilin International Marathon as an Example.Sporting goods and technology, (10):178-179.

[7] Yang Mao-yuan. (2018) The "Rational" Thinking Behind the "Sensibility" of China's Marathon. Journal of guangzhou institute of physical education, 38(06):58-62. 